\title{
A Probe into the Talent Training Mode of Vocational Colleges with " $1+X$ " Certificate System based on Credit Bank
}

\author{
Jinghui Ling, Daozhi Chen* \\ Beijing Union University, Beijing 100101, China \\ *Corresponding author: Daozhi Chen, cdz@buu.edu.cn
}

\begin{abstract}
Based on credit bank, the " $1+X$ " certificate system is a "flyover" for learners to interchange between the academic and vocational education. It is a significant innovation to promote high-quality vocational education development and enhance the influence of national vocational education. Vocational colleges can implement " $1+X$ " certificate system via the credit bank and in turn, the popularization of the " $1+X$ " certificate system would enrich and improve the former. China's development of the credit bank and the existing research on the " $1+X$ " certificate system are analyzed to look for a way in the collaboration of credit bank and the " $1+X$ " certificate system. The firm collaboration as well as the connection and optimization between government, schools, and enterprises as one body form a new talent training mode with the " $1+\mathrm{X}$ " certificate system that integrates academy and certificates as well as involving both, schools and enterprises according to China's credit bank concept.
\end{abstract}

Keywords: Credit bank; " $1+X$ " certificate system; Vocational colleges; "Three-in-one" talent training mode

Publication date: June 2021; Online publication: June 30, 2021

\section{Introduction}

Issued by the State Council on February 13, 2019, the National Program for Implementation of Vocational Education Reform has put forward that the vocational colleges as well as applied undergraduate colleges and universities should begin implementing the "Academic Diploma + Vocational Certificate" system. The standards and planning of the teaching curriculums should be determined by both the schools and enterprises. Students are then able to master better professional skills beyond their academic knowledge when academic education is combined with vocational education under the improvement of the "three-inone" model which enhances the vocational education and training system. It is not only the important reform decision of the 20 items in vocational education, but it is also a great innovation. Based on the credit bank concept, the " $1+X$ " certificate system is an important way to improve vocational education and training institutions, training and assessing integrated skilled talents, as well as a powerful measure to modernize the vocational education in building a country with excellent education to enhance the training quality of talents and eventually, producing high-quality labors and skilled talents.

\section{Domestic development of credit bank and research on " $1+X$ " certificate system}

\subsection{Domestic development of credit bank}

The concept of credit bank first emerged in America, then developed in Europe, and matured in Korea. In China, it is still being explored and the details are shown in Table 1. 
Table 1. History of credit bank policies

\begin{tabular}{cl}
\hline \multicolumn{1}{c}{ Time } & Events \\
\hline From mid-1990s & Colleges, universities, and vocational colleges started exploring and using the school credit system. \\
\hline 2005 & $\begin{array}{l}\text { The Ministry of Education emphasized the overall use of the credit system and the construction of } \\
\text { credit bank. }\end{array}$ \\
\hline 2006 & Secondary vocational colleges started the pilot credit bank. \\
\hline 2010 & $\begin{array}{l}\text { In the Outline of China's National Plan for Medium and Long-term Education Reform and } \\
\text { Development (2010-2020), the certification system and the credit bank were made as regulations. }\end{array}$ \\
\hline $\begin{array}{l}\text { Opinions on Accelerating the Development of Education by the Ministry of Education proposed the } \\
\text { building of different kinds of continuing education certification systems and school credit systems } \\
\text { that include the credit accumulation and transfer. } \\
\text { The fifth plenary session of the 18 }{ }^{\text {th }} \text { Communist Party of China (CPC) Central Committee declared } \\
\text { that the obstacles for continuing education and lifelong learning can be solved by creating personal } \\
\text { learning accounts and credit accumulation systems. }\end{array}$ \\
\hline
\end{tabular}

February 2017 The Minister of Education declared in the national education conference that the operation of credit bank would be explored and pilot work including continuing education certifications as well as credit accumulation and transfer would be continued.

\begin{tabular}{ll}
\hline November 2017 & The mark of China's credit bank entering into a rapid development in the official launch of "Online \\
& Credit Bank" - an open learning platform developed by the Open University of China and Chaoxing \\
& Group.
\end{tabular}

January 2019 National Program for the Implementation of Vocational Education Reform by the Ministry of Education suggested to speed up the construction of the credit bank system in vocational colleges.

April $2020 \quad$ In the education conference between departments of the State Council, the plan for a national credit bank for vocational education was examined and approved. The Work Procedure for the Building of National Credit Bank for Vocational Education (Trail) was formed.

November 2020 Beijing's credit bank project was initiated. By then, 16 provinces and cities had implemented credit banks. The state-level credit bank was at the design stage.

As the state encourages the exploration and implementation of credit bank, vocational colleges should also integrate the system and give full play to it. However, the occupation types and training centers vary from region to region because of their differences in locations, economy, and cultures.

\subsection{Domestic research on " $1+X$ " certificate system}

Approximately 1298 literatures about the " $1+X$ " certificate system can be indexed from China Academic Journals (CNKI) which provides plentiful theoretical basis and valuable practical experiences for pilot work. A few of these literatures are summarized in Table 2.

In April 2019, the Ministry of Education and three other departments issued On the Pilot Scheme of Implementing the System of "Diploma Certificate + Several Vocational Skill Level Certificates" in Colleges to ensure that the pilot works are scientific with regulatory and orderly proceedings. 
In October 2019, the Ministry of Education issued the Notification about Expanding the Pilot of " $1+X$ " Certificate System which declared that beyond the existing pilot institutions, any other universities or colleges with good foundation and are qualified for pilot work are allowed to participate in the pilot scheme.

In January 2020, the Institute of Vocational and Technical Education Center of the Ministry of Education issued the Notice on Confirming the Participation of the Third Batch of Vocational Education and Training Evaluation Organizations and Vocational Skilled Grade Certificates in the Pilot of " $1+X$ " Certificate System, which means that the pilot work of the " $1+X$ " certificate system has been gradually brought to the surface.

Table 2. Domestic research on " $1+X$ " certificate system

\begin{tabular}{|c|c|c|c|}
\hline Author & Subject & Research content & Study results \\
\hline $\begin{array}{c}\text { Guohong } \\
\text { Yu } \\
(2019)\end{array}$ & $\begin{array}{l}\text { Electronic } \\
\text { commerce } \\
\text { major in } \\
\text { vocational } \\
\text { colleges }\end{array}$ & $\begin{array}{l}\text { Construction of the " } 1+X " \\
\text { certificate system, analysis on } \\
\text { acquisition and assessment of } \\
\text { skill certificates, and the } \\
\text { differences between skill } \\
\text { certificates and qualification } \\
\text { certificates. }\end{array}$ & $\begin{array}{l}\text { 1. Based on the " } 1+X " \text { certificate system, the e-commerce } \\
\text { major should restructure its course setting to achieve resource } \\
\text { sharing, implement the combined training of skilled personnel, } \\
\text { and perfecting the school-enterprise " } 1+X \text { " certificate system. } \\
2 \text {. The integration of " } 1+X \text { " certificate system can ensure the } \\
\text { smooth implementation of industrial integration, promote the } \\
\text { improvement of students' skills, and achieve proper education. }\end{array}$ \\
\hline $\begin{array}{c}\text { Jianfeng } \\
\text { Deng } \\
\text { (2019) }\end{array}$ & $\begin{array}{l}\text { Vocational } \\
\text { colleges }\end{array}$ & $\begin{array}{l}\text { Construction of the " } 1+\mathrm{X} \text { " } \\
\text { certificate related management } \\
\text { system, identification of training } \\
\text { assessment institutions, } \\
\text { development of teaching } \\
\text { standards, establishment of } \\
\text { credit bank system, } \\
\text { strengthening the construction } \\
\text { of teachers, etc. }\end{array}$ & $\begin{array}{l}\text { 1. It has solved several problems that are not closely related to } \\
\text { vocational education, economic, and social development, as } \\
\text { well as drawn social forces to participate in vocational } \\
\text { education. } \\
\text { 2. As student-centered, it deepens the training of compound } \\
\text { technical mode and assessment mode, greatly improve the } \\
\text { training quality of relevant vocational education personnel, and } \\
\text { promote the rapid growth of skilled personnel which play } \\
\text { important roles in promoting employment and development. }\end{array}$ \\
\hline $\begin{array}{l}\text { Yiping } \\
\text { Du, } \\
\text { Haidong } \\
\text { Li, Bin } \\
\text { Zhan } \\
\text { (2019) }\end{array}$ & $\begin{array}{l}\text { Vocational } \\
\text { colleges }\end{array}$ & $\begin{array}{l}\text { Talent training mode through } \\
\text { the integration, interaction, and } \\
\text { mutual growth of colleges and } \\
\text { enterprises, in addition to the } \\
\text { three-point curriculum system } \\
\text { of courses and certificates. }\end{array}$ & $\begin{array}{l}\text { 1. Problems with issuing subjects of "X" certificate, } \\
\text { determination of the certificate levels, and the connection with } \\
\text { academic certificates need to be solved. } \\
\text { 2. The certification subject should be decided by the } \\
\text { government and other authoritative departments. It is integrated } \\
\text { into enterprises' existing certification system for professional } \\
\text { grades. }\end{array}$ \\
\hline
\end{tabular}

In view of the research status of domestic scholars, majority of them focus on the study of national policies and have conducted in-depth studies on the analysis and implementation of vocational education policies. Several scholars have also contributed their own opinions and suggestions on the current talent training mode. The talent training mode of vocational colleges in China is currently in the preliminary stage of exploration and it still requires a lot of time to study, investigate, and analyze in order to understand its shortcomings prior suggesting optimization efforts. 


\section{Collaboration between credit bank and the " $1+X$ " certificate system}

Based on the concept of credit bank, the " $1+X$ " certificate system encourages students to acquire multiple vocational skill level certificates while obtaining their academic certificates at school. In other words, students can simultaneously meet the teaching objectives of two types of education through one study and avoid repetition of learning contents to improve their learning efficiency.

Credit banks specify the standards for the " $1+X$ " certificates and manage them in different levels and classifications. Academic credits are recognized as the key measure when learners meet the conditions of certain academic qualifications and the cultivation of certain vocational skills.

The collaboration of the two aspects interconnects the professional teaching assessment and the professional skill certification. The introduction of the " $1+X$ " certificate system provides a logical basis and practical reference for the construction of the credit bank. As a "flyover" for the accumulation, transformation, and saving of training, the credit bank transforms the education mode, breaks through the limitation of time and space in education, and provides an opportunity for the training of talents with character and innovation.

\section{Construction of " $1+X$ " certificate system based on credit bank in vocational colleges}

\subsection{Operation process of " $1+X$ " certificate system based on the credit bank concept}

Through literature research, it is found that the operation process is supported by relevant policies of the government, actively promoted by schools, as well as recognized by enterprises, and the personnel training objectives of vocational colleges meet the demands of the social and economic development. In view of the three parties involved in talent training, the operation process of credit bank and the " $1+X$ " certificate system based on the "three-in-one" model is established as shown in Figure 1.

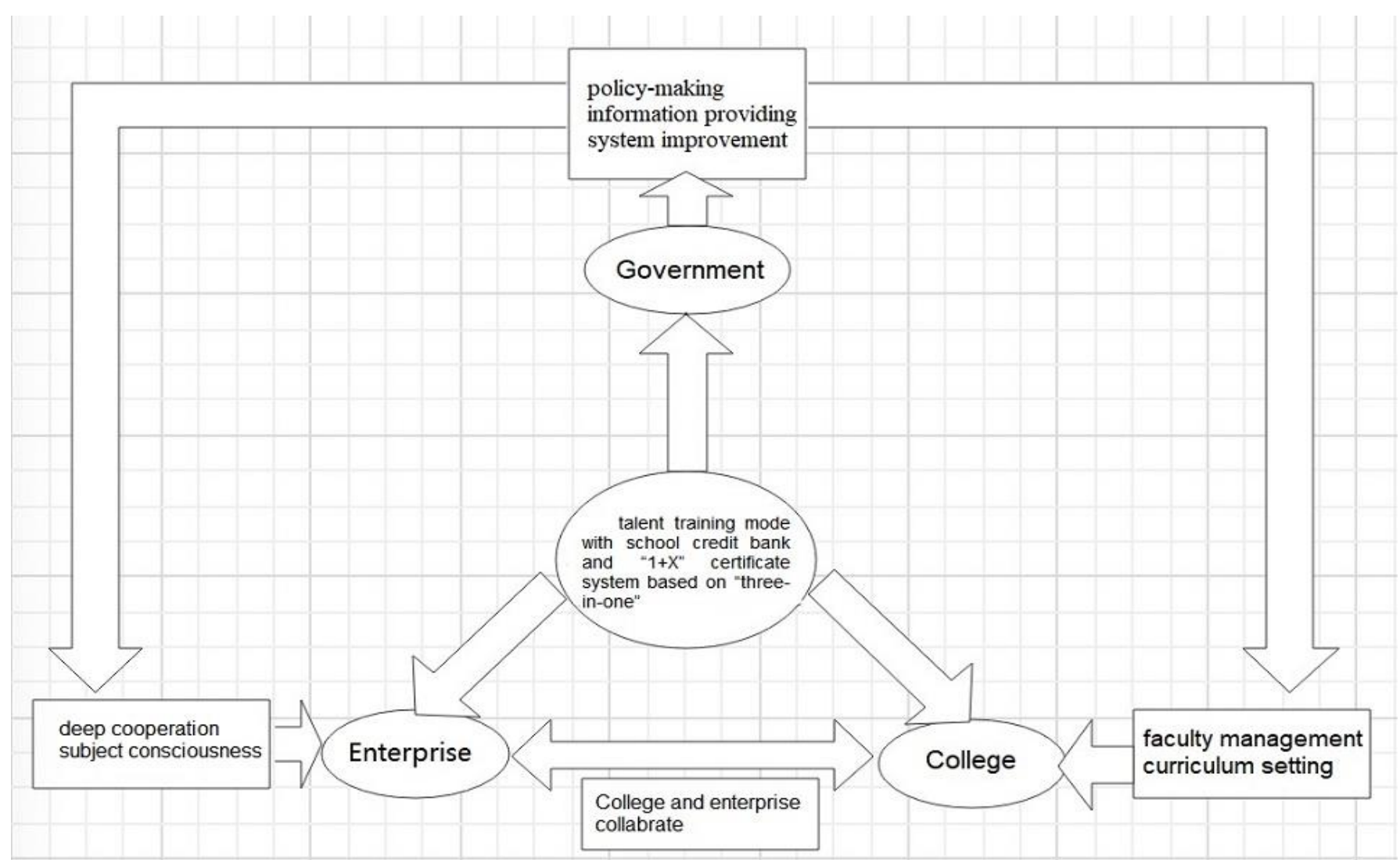

Figure 1. Operation process of credit bank and the " $1+X$ " certificate system based on the "three-in-one" model 


\subsection{Building credit bank and " $1+X$ " certificate system in vocational colleges}

Vocational education is an educational system with a purpose to train professional talents needed by the society in terms of theory, ethics, and practice for certain professions while abiding by the government's regulations. Instead of the simple addition of diploma and vocational certificates, it requires appropriate teaching contents and practices built based on the "three-in-one" model that includes the government, colleges, and enterprises as it is closely related to the future positions of the students.

\subsubsection{Government: Building communication program and completing the " $1+X$ " institutional framework}

The government's support and lead play important roles in the certification of vocational grade certificates. In order to provide better services, the government needs to use resources to build online information platforms for colleges and enterprises, increase the communication between colleges and enterprises, as well as to have better understanding about these parties.

\subsubsection{Colleges: Improving teaching faculty and curriculum}

Colleges are the main institutions to implement the talent training mode of the " $1+X$ " certificate system. The quality of talent training is affected by the curriculum settings as well as the quality of faculties. The construction of the team of "double type" teachers should be strengthened and regularly trained in regard to the vocational grade certificates along with the standards of " $\mathrm{X}$ " certificate, so that they would be able to understand the " $1+X$ " certificate system better. In this way, the teachers' ability to integrate vocation into academy can be improved while the courses can be assembled in accordance with characteristics of vocational colleges, diplomas, and skill level requirements, hence perfecting the curriculum system.

\subsubsection{Enterprises: Participation in cooperation and completion of career system}

Enterprises should enhance their participation of personnel training in vocational colleges. They should actively participate in professional construction, training base construction, and students' internships by providing ideas in developing vocational education that is related to corresponding sectors, offering practices beyond study, promoting the deep integration of vocational education chain into the industrial chain, and effectively serving the economic and social development.

\section{Talent training mode with the " $1+X$ " certificate system based on credit bank in vocational colleges}

With the " $1+X$ " certificate system, the methods and means of vocational education reform can be enhanced, the relevant advantages of credit banks can be made used to take root in the professional environment, and the talent training mode for vocational education can be built in the organic combination of the two.

\subsection{Establishing the talent training mode with courses in line with certificates}

To actively promote the dual certificate system and explore the talent training mode of the " $1+X$ " certificate system, it is necessary to first discuss the relationship and application of " 1 " and "X," and whether they are complementary or independent to each other. In that case, there is a need to analyze the contents of the certificate assessment and decide according to the situation of specialty courses in schools. The teaching system of integrating courses and certificates should be based on the direction of credit bank and social development, meeting the requirements of vocational positions, understanding the trends of occupation, organically adjusting career development plans, in addition to improving the quality, cultivating, enhancing the value, and empowering vocational education. 


\subsection{Establishing a talent training mode assisted by competition}

With professional skills contest, the credit bank and the " $1+X$ " skills under the guidance of diversified talent training mode can be explored. Through competitions, the " $1+X$ " certificate system can be integrated into teaching to realize the tight connection between the two and improve students' operating ability, thus seamlessly integrating the " $1+X$ " certificate system into professional classroom teachings. In this way, it does not only improves students' professional and practical skills but also enhances the teachers' teaching level and professional quality which is a win-win situation.

\subsection{Building talent training mode}

In view of the college-enterprise dual-subject teaching mode, the guarantee mechanism under the " $1+X$ " certificate system based on the credit bank concept is actively explored. The college-enterprise joint training agreement is formed by the design of framework agreements, formulation of relevant cooperation contents, deeply exploration of the operation mechanism, construction of practical training base, recruitments and employments, cooperation between productions, as well as education and research. In this way, a high degree of teaching and occupation integration as well as point-to-point employments can be achieved.

\section{Conclusion}

Vocational colleges are responsible for training high-quality labors and skilled talents by applying the " $1+\mathrm{X}$ " certificate system based on the concept of credit bank. The government supports with macro policies and colleges design the curriculums based on theories and practices while enterprises offer opportunities to practice together in order to integrate talents with professional skills as well as other skills. Vocational colleges should begin a new round of profession construction, curriculum reform, promotion of doublequalified teachers", and innovation of talent assessments in their implementation of the " $1+X$ " certificate system based on credit bank.

Although the " $1+X$ " certificate system based on credit bank has been completely promoted, it is still developing contents, including certificates as well as training assessments, and so on. It neither shows the cumulative effect of these certificates nor have any files which would guide the circulation of certificates. It can only ease the issue of structural contradictions in social employments and students' employment pressure, but it does not profoundly raise the overall social education quality which would be a waste of education resources. Hence, vocational colleges should dialectically examine this talent training mode and constantly modify it based on the policies and practical results.

\section{Funding}

Supported by Beijing Young Famous Teachers Program "Research on the telepresence in online class under the background of mobile internet background."

\section{Disclosure statement}

The author declares no conflict of interest.

\section{References}

[1] Cheng ST, 2020, Research on the synergistic development of credit banks and 1+X certificate system of qualification framework. Vocational \& Technical Education Forum, 36(12): 38-44.

[2] Li SB, Gao YF, Yang XF, 2020, Present situation and countermeasures of 1+X certificate system of 
vocational education. Vocational and Technical Education, 41(20): 20-24.

[3] Qi YL, 2019, The current predicament and countermeasures of credit bank construction in our country. Education and Profession, (06): 78-83.

[4] Jiang Y, 2018, Research on the connecting mode of middle and higher vocational education based on credit bank model. Contemporary Vocational Education, (02): 29-36.

[5] Yu GH, 2019, Exploration on construction of electronic commerce technology major in higher vocational colleges based on 1+X certificate system. Office Automation, 24(20): 30-2.

[6] Deng JF, 2019, Study on the reform of talent training mode of vocational education under $1+\mathrm{X}$ certificate system. Auto Time, (17): 49-50.

[7] Wang ZQ, 2019, Discussion on the application of " $1+X$ " certificate system in vocational colleges from the basis of ability. Gansu Education, (16): 42-3.

[8] Du YP, Li DH, Zhan B, 2019, Discussion on the design of 1+X certificate system from the perspective of "coexistence and common growth of courses and certificates". The Chinese Society For Technical And Vocational Education, (04): 9-14. 